\title{
eHealth Literacy and Self-care Behavior during the Coronavirus Disease-19 Pandemic among Youths: A Path Analysis
}

\author{
Daniel ChriswinantoAdityo Nugroho $^{1}$ (D), Dedik Sulistiawan ${ }^{2 *}$ (D) Riza FatmaArifa $^{3}$ (D) Maria Gayatri ${ }^{4}$, Mardiana DwiPuspitasari ${ }^{4}$ (D), \\ Fuad Wahyu Prabowo ${ }^{5}$ (iD \\ ${ }^{1}$ Department of Public Health and Family Medicine, Universitas Kristen Duta Wacana, Yogyakarta, Indonesia; ${ }^{2}$ Department of \\ Public Health, Universitas Ahmad Dahlan, Yogyakarta, Indonesia; ${ }^{3}$ National Population and Family Planning Board, Special \\ Region of Yogyakarta Representative, Yogyakarta, Indonesia; ${ }^{4}$ National Population and Family Planning Board, Jakarta, \\ Indonesia; ${ }^{5}$ Graduate Program, UIN Sunan Kalijaga, Yogyakarta, Indonesia
}

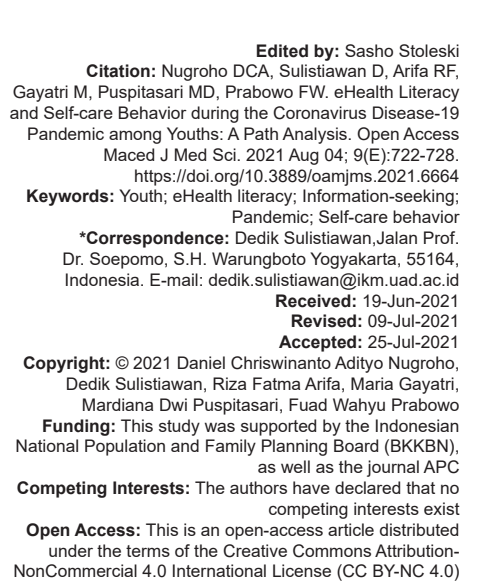

Introduction

Disseminating the National coronavirus disease (COVID-19) Infection Prevention Guidance has been a public health program to slow infection spread across the country. As the cases of covid-19 continue to rise, there is also increasing public concern about the limitation of physical contact. This disorder tends to drive individuals to access health information and services online. The utilization of information and communication technologies for health-related issues, including health promotion, health surveillance, health care service, and research is then described as eHealth according to $\mathrm{WHO}$. This definition is an extension of the explanation of telemedicine, which is limited to health care services [1]. Along with the development of technology, mHealth emerges as a component of eHealth, allowing medical services and surveillance to be carried out via a mobile phone and other wireless devices [2].
Previous research showed that younger individuals, educated, self-confident, and benefit from online health information are related to online health resources [3], [4], [5]. Youths have an increasing propensity to use the internet as their source of health knowledge, but these teens have been restricted to knowing and applying this online information to their everyday lives [4]. Exposure to the media may give youths a chance to obtain false news, hoax, and even unlawful conduct, particularly during the period of the covid-19 pandemic [6], [7], [8], [9]. Besides, misleading information on covid-19 etiology, preventive and curative social media behavior has harmed physical and mental health [8], [9].

Therefore, eHealth literacy is especially relevant for youths at the time of covid-19 infection so that the health information they receive enhances their health outcomes. The end-users' education level must also be addressed to advance eHealth's benefit in selfhealth management [10]. Norman and Skinner defined eHealth literacy as "the ability to seek, find, understand, 
and appraise health information from electronic sources and apply the knowledge gained to addressing or solving a health problem" [11].

Following the theory of planned behavior (TPB), we note a literature discussion on the cognitive and affective mechanism of how eHealth literacy can contribute to self-health behavior. Even though there is no definitive evidence of a link between TPB and electronic health literacy, previous research has suggested that they are interrelated [12]. Initially, the TPB is a behavioral success model with intentions as predictive behavior, whereas intentions are evaluated by attitude, subjective norms, and perceived behavior control. Furthermore, perceived behavior control is often thought to have a direct effect on behavior. There is criticism that the TPB is a too logical model by neglecting the cognitive and affective process through which human decisions and actions are considered prejudiced [13].

In the sense of eHealth literacy, several studies are trying to discover how eHealth literacy can affect one's health behavior by applying the TPB model. Originally, eHealth literacy is intended to motivate individuals and allow them to make health-related choices by using eHealth tools [11]. Research indicated that eHealth literacy directly impacts behavioral intentions and health behavior [12]. As far as our knowledge is concerned, there is little evidence of the relationship between eHealth literacy and current health behavior, especially at the covid-19 pandemic. A prior study found that under threat to health, youths who have a high degree of control over decisions and behaviors are more likely to have intentions to manage their health by using eHealth information [14]. Further studies on eHealth literacy and health behavior during the duration of covid-19 are therefore required.

Considering the role of end-user education in the eHealth strategy [10], our study focuses on Yogyakarta, Indonesia. Yogyakarta has approximately $88.95 \%$ students aged $16-18$ years and $51.81 \%$ students aged 19-24 years in 2020. Moreover, it becomes the province with the highest school participation rate in Indonesia [15]. However, the Programme from International Student Assessment (PISA) 2018 found that students in Indonesia scored lower than the OECD average in reading, mathematics, and science. Although Yogyakarta is the province with the highest PISA score in Indonesia, its position is still below the OECD average and several other Asian countries such as Singapore and Malaysia [16]. We conclude that the level of education cannot reflect Yogyakarta students' level of literacy, because eHealth literacy involved reading and science skills, working knowledge of the computers, understanding social context, and health literacy [11], [17].

Because of the covid-19 pandemic, the high prevalence of Indonesian students studying in Yogyakarta, and the embedded problem of online health resources, this study was planned to address eHealth literacy and its related self-health management based on current behavior among youths aged 15-24 years in Yogyakarta. In this research, we targeted youths because of their age of study. Following the TPB, we also need to examine the association's cognitive mechanism between eHealth literacy and current health behavior among youths in Yogyakarta.

\section{Methods}

\section{Design and participants}

This cross-sectional study was an online survey administered from October 5 to October 19, 2020. The inclusion criteria for this research were male and female youths aged 15-24 years (according to WHO category [18]), never married, and lived in the Special Region of Yogyakarta, consisting of five Districts/City: Yogyakarta, Bantul, Kulon Progo, Sleman, and Gunung Kidul. Subjects were then invited to participate in the online survey through LimeSurvey [19].

Samples were determined based on voluntary non-probability sampling approach, citing limitations in the sample recruitment process in the online survey which made it impossible to apply the probability sampling method [20]. Respondents in this study were subjects who met the inclusion criteria who voluntarily responded to the online questionnaire during the survey period. Taking into account the margin of error of $5 \%$ and the estimated number of youths in the Special Region of Yogyakarta around 561,564 [21], the minimum targeted sample size is 384 respondents. To anticipate an incomplete response, we added $10 \%$ from the minimum targeted sample size. Therefore, the estimated response rate was $90 \%$, or equivalent to 422 respondents.

\section{Measurements}

Before conducting inferential statistical analysis, a reliability test was needed due to indicators of health behavior, eHealth literacy, intentions, behavioral control, and subjective norms were measured using a Likert scale. All indicators have Raykov's factor reliability coefficient (RRC) greater than 0.7 (ranged from 0.7 to 0.9 ). This shows that the instrument used has a sufficient reliability value (sufficient reliability) [22].

\section{eHealth literacy}

In this study, eHealth literacy was assessed by the eHealth Literacy Scale (eHEALS), which consisted of 8-items scored on a 5-point Likert scale between 1 (strongly disagree) and 5 (strongly 
agree). eHEALS was developed to measure perceived expertise in the search, appraisal, and implementation of electronic health information based on the internet [23]. The sentences to measure this variable were such as "I have the skills I need to evaluate the health resources I find on the internet," and "I feel confident in using information from the internet to make health decisions" [23].

\section{Health information-seeking behaviors}

This variable was measured using a questionnaire on participants' demographic background, health status, frequency, the pattern of online health information seeking, subjects, sources, and motivations for online health information seeking [24].

\section{The intention of health maintenance}

The variable was used to assess youth intention in health self-maintenance based on the American College Health Association (ACHA) recommendation, which was design according to the TPB. The instrument consisted of 8 areas of health issues such as overall health, exercise regime, maintaining a lifestyle free of hazardous drugs, sleep, vaccinations, maintaining safe sex practices, maintaining a balanced diet, and maintaining a positive social relationship [12]. The questionnaire used a 5-point Likert scale.

\section{Self-maintenance of health behavior}

The variable was measured using a 5-point Likert scale instrument about youths' activities on selfmaintenance of their health behavior based on the recommendation of $\mathrm{ACHA}$ [12].

\section{Perceived behavioral control}

The variable was measured based on the TPB, which asked how confident are the youths on selfmaintenance of their health behavior based on ACHA recommendation [12].

\section{Subjective norms on health maintenance}

The variable was measured to determine youths' approval in self-maintenance of their health behavior based on ACHA recommendations according to their subjective beliefs [12].

\section{Attitude toward health maintenance}

The variable was measured using an instrument that design, according to TPB, which asked attitudes in carrying out personal health based on ACHA recommendation [12].

\section{Statistical analysis}

Statistical analysis included descriptive statistics to present sociodemographic, sociocognitive, eHealth literacy, and health behavior characteristics. $\mathrm{RRC}$ was used to assess scale reliability. The construct will be reliable if the value of $R R C \geq 0.7$ [22]. We were also performing principal-component factor analysis to obtain the eHealth literacy and health behavior indexes. The indexes formed were used to build the path model. Besides, we grouped the indexes into two categories, "good" if its value above the factor score and "poor" if its value below the factor score, and presented it in the descriptive statistics.

Moreover, path analysis was used to determine factors influencing eHealth literacy and health behavior among Yogyakarta youths. The performance of the final model was measured by the Likelihood ratio Chi-square test and the goodness of fit indices, such as Root Mean Square Error of Approximation (RMSEA), Tacker-Lewis index (TLI), and comparative fit index (CFI). Values for TLI and CFI varies from zero to 1 , with suggested values higher than 0.90 representing a good fit. There is a good fit if RMSEA is fewer than 0.08. All analyses were performed using STATA version 15.1 [25].

\section{Ethics statement}

This research was approved by the Ethics Review Committee of Universitas Kristen Duta Wacana, Faculty of Medicine, for research and publication purposes (Number: 1213/C.16/FK/2020). Subjects were allowed to sign the form after informed consent was obtained. Due to ethical considerations, youths aged 15-17 provided parents' approval before participating in the survey.

\section{Results}

A total of 455 youths with full responses were included in the final sample. Most of the respondents are female $(79.8 \%)$, live with parents $(81.1 \%)$, currently attending or graduated from college $(50.8 \%)$, and studying from home during the COVID-19 outbreak (81.3\%).

\section{Youth self-care behaviors}

More than half of the respondents belong to the group of youths with good self-care behavior. Based on other characteristics, the proportion of youths aged 15-19 years who had good self-care behavior was more remarkable than those aged 20-24 years. Besides, youths who lived with their parents also tended to have good self-care behavior-youths who did not work or studied tended to have poor health behavior (Table 1). 
Table 1: Adolescent self-care behaviors according to sociodemographic characteristics

\begin{tabular}{|c|c|c|c|}
\hline \multirow[t]{2}{*}{ Variable } & \multicolumn{3}{|c|}{ Self-care behavior } \\
\hline & $\begin{array}{l}\text { Poor } \\
\text { (\%) }\end{array}$ & $\begin{array}{l}\text { Good } \\
(\%)\end{array}$ & $\begin{array}{l}\text { Total } \\
\mathrm{n}\end{array}$ \\
\hline \multicolumn{4}{|l|}{ Gender } \\
\hline Male & 37.0 & 63.0 & 92 \\
\hline Female & 48.2 & 51.8 & 363 \\
\hline \multicolumn{4}{|l|}{ Age category } \\
\hline $15-19$ & 39.7 & 60.3 & 234 \\
\hline $20-24$ & 52.5 & 47.5 & 221 \\
\hline \multicolumn{4}{|l|}{ Educational attainment } \\
\hline Junior high school & 35.7 & 64.3 & 56 \\
\hline Senior high school & 42.9 & 57.1 & 168 \\
\hline Academy/ university & 50.6 & 49.4 & 231 \\
\hline \multicolumn{4}{|l|}{ Living with parents } \\
\hline Yes & 43.4 & 56.6 & 369 \\
\hline No & 57.0 & 43.0 & 86 \\
\hline \multicolumn{4}{|l|}{ Parent's educational attainment } \\
\hline Senior high school or less & 44.8 & 55.2 & 277 \\
\hline Academy/university & 47.8 & 52.2 & 178 \\
\hline \multicolumn{4}{|c|}{ The main activities carried out during the COVID-19 emergency } \\
\hline Study from home & 45.1 & 54.9 & 370 \\
\hline Work from home & 40.0 & 60.0 & 20 \\
\hline Study in the school & 50.0 & 50.0 & 6 \\
\hline Work in the office & 47.2 & 52.8 & 36 \\
\hline Did not working/studying & 60.9 & 39.1 & 23 \\
\hline Total & 45.9 & 54.1 & 455 \\
\hline
\end{tabular}

\section{Youth ehealth literacy and health information-seeking behavior}

The survey indicates that $93 \%$ of youths used smartphones to access the internet almost every day. During the covid-19 pandemic, youths learned the value of improving personal wellbeing, such as worrying about the symptoms they were having $(78 \%)$, latest health information updates $(74 \%)$, and want to improve their behavior to be healthy $(65 \%)$. This was also reflected in the situation in which 3 out of 4 youths searched for health information online about the disease's types and symptoms and healthy behavior (diet, exercise, etc.) via YouTube, social media, and commercial health sites.

Although five in 10 youths accessed the internet more than $4 \mathrm{~h}$ a day, the survey shows that more than half of youths had low eHealth literacy levels. The construct that had the highest score coefficient was known where to obtain health information on the internet (0.81), how to find it (0.82), and how to use it (0.78) (Figure 1). More than half of youths who had sought health information online had never confirmed the accuracy of the information they obtain through online or offline consultations with health workers.

\section{behavior}

\section{Factors associated with youth self-care}

Figure 2 represents the best model for path analysis. Path coefficients were determined using a sequence of analyzes based on the hypothesized research model described in Figure 2 and Table 2. The final model indicating a good fit with the Likelihood ratio Chi-square $3.54(p=0.06)$, RSMEA scores 0.07, CFI 0.99 , and TLI 0.96, which implies that the model could explain the inter-relationship between the variables effectively. Intention $(\beta=0.09 ; 95 \% \mathrm{Cl}=0.01-0.18$; $p=0.037)$, perceived behavioral control $(\beta=0.46$; $95 \% \mathrm{Cl}=0.38-0.54 ; \mathrm{p} \leq 0.001)$, and subjective norms $(\beta=0.24 ; 95 \% \mathrm{Cl}=0.16-0.33 ; \mathrm{p} \leq 0.001)$ had a significant positive direct effect on youth selfcare behavior. Perceived behavioral control has the strongest effect on youth self-care behavior, among others. Even tough attitude toward the behavior did not have a significant direct effect on self-care behavior, this factor indirectly affects self-care behavior through the intention $(\beta=0.46 ; 95 \% \mathrm{Cl}=0.39-0.53 ; p \leq 0.001)$ together with eHealth literacy $(\beta=0.11 ; 95 \% \mathrm{Cl}=0.04$ $0.18 ; p=0.001$ ). The contributing factors contributed for $70 \%$ of the variance in understanding youth self-care behaviors (Table 2).

\section{Discussion}

The Covid-19 pandemic first spread not only offline but also online. The internet, with its multiple capillary communication capabilities, generously provides global information, creates sincere hope and paranoia simultaneously, and provides data on the number of ill and dead people identified with an accuracy of up to millimeters per day. Besides, the community has also begun seeking information on prevention and healthy behavior to stop the virus's spread, including youths.

These findings indicate that almost all youths used the internet to look for health information during the pandemic time. The types of health information frequently searched were disease symptoms, disease types, and healthy lifestyles such as diet, exercise, and many more. It might be because youths did not do physical exercise during the pandemic. Youths want to stay healthy by maintaining a good body image; therefore, they should seek certain health information, such as diet and exercise.

This usually confirms that the public sees the Internet as an essential source of health information. This is in line with recent studies in Wuhan, where the epidemic began. Most of these users are youths and older people who seek health information and assistance from their parents or older adults at home. The most sought-after information includes access

Table 2: Path coefficient based on the final mode

\begin{tabular}{|c|c|c|c|c|c|c|}
\hline \multirow[t]{2}{*}{ Dependent variable } & & \multirow[t]{2}{*}{ Independent variable } & \multirow[t]{2}{*}{$\beta$} & \multicolumn{2}{|l|}{$95 \% \mathrm{Cl}$} & \multirow[t]{2}{*}{$p$-value } \\
\hline & & & & $\begin{array}{l}\text { Lower } \\
\text { bound }\end{array}$ & $\begin{array}{l}\text { Upper } \\
\text { bound }\end{array}$ & \\
\hline \multicolumn{7}{|l|}{ Direct effect } \\
\hline \multirow[t]{4}{*}{ Self-care behavior } & $\leftarrow$ & Intention & 0.09 & 0.01 & 0.18 & 0.037 \\
\hline & $\leftarrow$ & Perceived behavioral control & 0.46 & 0.38 & 0.54 & $<0.001$ \\
\hline & $\leftarrow$ & Subjective norms & 0.24 & 0.16 & 0.33 & $<0.001$ \\
\hline & $\leftarrow$ & Attitude toward the behavior & 0.07 & -0.01 & 0.15 & 0.074 \\
\hline \multicolumn{7}{|l|}{ Indirect effect } \\
\hline \multirow[t]{4}{*}{ Intention } & $\leftarrow$ & Perceived behavioral control & 0.21 & 0.13 & 0.29 & $<0.001$ \\
\hline & $\leftarrow$ & Subjective norms & 0.17 & 0.09 & 0.25 & $<0.001$ \\
\hline & $\leftarrow$ & Attitude toward the behavior & 0.46 & 0.39 & 0.53 & $<0.001$ \\
\hline & $\leftarrow$ & eHealth literacy & 0.11 & 0.04 & 0.18 & 0.001 \\
\hline $\begin{array}{l}\text { Sample size = 455 } \\
\text { Likelihood ratio Chi-squ } \\
\text { Root mean squared err } \\
\text { Comparative fit index (C } \\
\text { Tucker-Lewis index (TL } \\
\text { Coefficient of determina }\end{array}$ & & $\begin{array}{l}\text { value })=3.54(0.060) \\
\text { proximation }(\text { RMSEA })=0.075 \\
.996 \\
66 \\
D)=0.699 .\end{array}$ & & & & \\
\hline
\end{tabular}




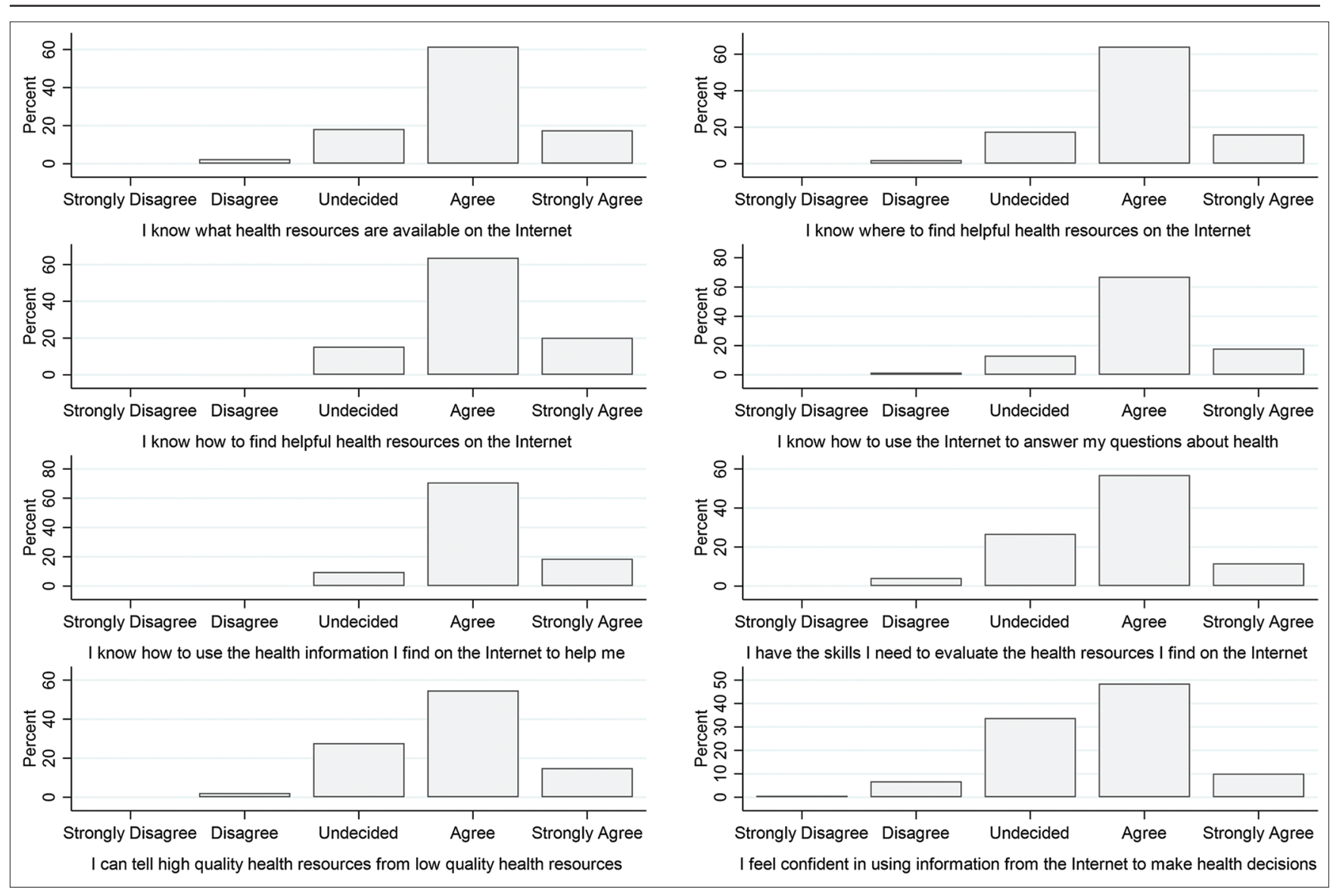

Figure 1: Adolescents ehealth literacy scale

to medical care, self-quarantine management, and online support. [26]. Participating youths appear to be well informed about protective behaviors, such as handwashing [27]. Most youths have also begun to adopt positive behavioral practices to prevent the spread of infection immediately after receiving messages about Covid-19 [28].

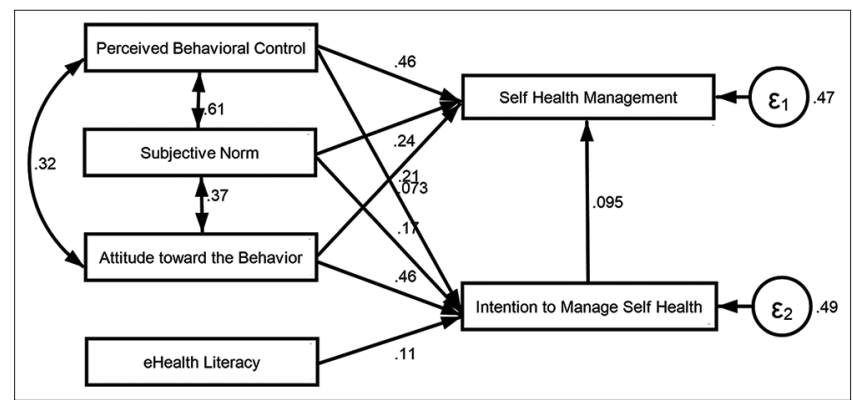

Figure 2: Final path model

The sources of health information accessible to youths often differ. They were most likely to access video sharing sites (e.g., YouTube), commercial health sites (e.g., Halodoc), web encyclopedias (e.g., Wikipedia), and social media (e.g., WhatsApp and LINE). More than half of the youths did this several times a week. However, only about a quarter of respondents stated that they had used telemedicine services during the pandemic period, and less than forty percent ever ask or discuss with the doctors/health workers about the health information found online. This condition potentially allowed youths to have difficulty in understanding or using online health information. Even though the youth groups were familiar with information technology, many of them did not benefit from the use of information technology [29]. This suggested that eHealth literacy needed to be prioritized to carefully sort out and utilize any information on the internet [30]; therefore, they can live better in a pandemic situation.

The utilization of health resources, primarily preventive services, such as the availability of information about specific habits and issues (smoking, family planning, diet, etc.) is growing following the rise in health literacy. Literacy and quality of health are said to be closely linked [31]. Even though eHealth literacy did not directly affect self-care behavior, this factor was important because it builds youth's intention to conduct a healthy behavior or not. It seems that the good effect of intention on improving self-health care behavior would only occur when it was followed by good eHealth literacy and good behavior factors, i.e. perceived behavioral control, subjective norms, and attitude toward the behavior. Interventions on literacy skills could help on reducing intentions towards risky health behavior in youths [32]. Subjective norms, which could be perceived as how others react to someone's behavior, significantly affect self-care behavior directly and through other behavioral factors. Negative norms, 
such as stigma, would negatively affect youth attitude, perceived behavioral control, and reluctance to do proper healthy behavior [33].

In evaluating the findings, certain possible shortcomings should be considered. First, the survey's nature was cross-sectional, so we can only explain the relationships between the variables examined, not the causal relationship. Prospective research is expected to demonstrate causality. Second, this study was conducted with non-probability sampling through an internet-based survey. Its generalization was then constrained. Besides, the sample age range was considerably wide, and we did not conduct the stratification method, even though there were differences in characteristics between early and late adolescence. Upcoming studies should consider age stratification to address this issue. Moreover, there was a possible risk of self-selection bias in this study because of the nature of the online surveys which more likely to be enrolled by tech-savvy youths who are literate and who have access to the internet. Forthcoming studies on eHealth literacy could incorporate offline surveys to engage an enormous variety of youths.

\section{Conclusion}

In conclusion, this study found that health literacy does not directly affect health behavior, but this factor becomes essential because it builds youths' intention to behave healthier. The positive impact of intention to enhance self-health care seems to have occurred only if eHealth literacy was adopted. This research requires further inquiry into youth health literacy, perhaps through a prospective design. The findings of this study are beneficial for the creation of successful eHealth literacy programs in youths.

\section{Acknowledgment}

The authors would like to express their gratitude to the Indonesian National Population and Family Planning Board's peer reviewers for the insightful and constructive recommendations during the planning and development of this research.

\section{References}

1. World Health Organization. Telemedicine: Opportunities and Developments in Member States: Report on the Second Global Survey on eHealth 2009 (Global Observatory for eHealth
Series). Vol. 2. Geneva: World Health Organization; 2010. https://doi.org/10.4258/hir.2012.18.2.153

2. World Health Organization. mHealth: New Horizons for Health Through Mobile Technologies: Second Global Survey on eHealth. Global Observatory for eHealth Series. Vol. 3. Geneva: World Health Organization; 2011. https://doi.org/10.4258/ hir.2012.18.3.231

3. Tennant B, Stellefson M, Dodd V, Chaney B, Chaney D, Paige S, et al. eHealth literacy and Web 2.0 health information seeking behaviors among baby boomers and older adults. J Med Internet Res. 2015;17:e70. https://doi.org/10.2196/jmir.3992 PMid:25783036

4. Gray NJ, Klein JD, Noyce PR, Sesselberg TS, Cantrill JA Health information-seeking behaviour in adolescence: The place of the internet. Soc Sci Med. 2005;60:1467-78. https://doi. org/10.1016/j.socscimed.2004.08.010

PMid: 15652680

5. Ren C, Deng Z, Hong Z, Zhang W. Health information in the digital age: An empirical study of the perceived benefits and costs of seeking and using health information from online sources. Health Info Libr J. 2019;36(2):153-67. https://doi. org/10.1111/hir.12250

PMid:30737878

6. Gradon K. Crime in the time of the plague: Fake news pandemic and the challenges to law-enforcement and intelligence community. Soc Regist. 2020;4:133-48. https://doi. org/10.14746/sr.2020.4.2.10

7. Mian A, Khan S. Coronavirus: The spread of misinformation BMC Med. 2020;18(1):89.

PMid:32188445

8. Rosenberg H, Syed S, Rezaie S. The twitter pandemic: The critical role of twitter in the dissemination of medical information and misinformation during the COVID-19 pandemic. CJEM. 2020;22(4):418-21. https://doi.org/10.1017/cem.2020.361 PMid:32248871

9. Tasnim S, Hossain MM, Mazumder H. Impact of rumors or misinformation on coronavirus disease (COVID-19) in social media. Can J Emerg Med. 2020;53:171-4. https://doi. org/10.3961/jpmph.20.094

10. Hilberts S, Gray K. Education as ehealth infrastructure: Considerations in advancing a national agenda for ehealth. Adv Health Sci Educ. 2014;19:115-27. https://doi.org/10.1007/ s10459-013-9442-z

11. Norman CD, Skinner HA. eHealth literacy: Essential skills for consumer health in a networked world. J Med Internet Res. 2006;8(2):e9. https://doi.org/10.2196/jmir.8.2.e9 PMid:16867972

12. Britt RK, Collins WB, Wilson K, Linnemeier G, Englebert AM. eHealth literacy and health behaviors affecting modern college students: A pilot study of issues identified by the American college health association. J Med Internet Res. 2017;19:e392. https://doi.org/10.2196/jmir.3100 PMid:29258979

13. Ajzen I. The theory of planned behaviour: Reactions and reflections. Psychol Health. 2011;26(9):1113-27. PMid:21929476

14. Goonawardene N, Jiang J, Tan SS, Jiang Z. Online health information seeking and dolescents' intention towards health self-management. In: Proceedings-Pacific Asia Conference on Information Systems, PACIS 2013; 2013.

15. Indonesia's Central Statistics Agency. Portrait of Indonesian Education: Education Statistics. Jakarta: Indonesia's Central Statistics Agency; 2020.

16. OECD. The Programme for International Student 2018 Result: Country Note-Indonesia. Paris: OECD; 2019. 
17. Mackert M, Champlin SE, Holton A, Munoz II, Damásio MJ. eHealth and health literacy: A research methodology review. J Comput Mediat Commun. 2014;19:516-28. https://doi. org/10.1111/jcc4.12044

18. World Health Organization. Adolescent health in the SouthEast Asia Region. Geneva: World Health Organization; 2021. Available from: https://www.who.int/southeastasia/health-topics/ adolescent-health. [Last accessed on 2021 Jun 04]. https://doi. org/10.4103/2224-3151.213789

19. Limesurvey $\mathrm{GmbH}$. LimeSurvey: An Open Source Survey Tool. Hamburg, Germany: LimeSurvey $\mathrm{GmbH} ; 2003$.

20. Fielding NG, Lee RM, Blank G, editors. The SAGE Handbook of Online Research Methods. $2^{\text {nd }}$ ed. United States: SAGE Publication Ltd.; 2017.

21. BPS Provinsi DIY. Provinsi Daerah Istimewa Yogyakarta dalam Angka 2020. Yogyakarta: Badan Pusat Statistik Provinsi Daerah Istimewa Yogyakarta; 2020. https://doi.org/10.18196/ rab.040150

22. Mehmetoglu M, Jakobsen TG. Applied Statistics Using Stata: A Guide for the Social Sciences. London: SAGE Publications Ltd.; 2017.

23. Norman CD, Skinner HA. eHEALS: The eHealth literacy scale. J Med Internet Res. 2006;8(4):e27. https://doi.org/10.2196/ jmir.8.4.e27

PMid: 17213046

24. Wong DK, Cheung MK. Online health information seeking and ehealth literacy among patients attending a primary care clinic in Hong Kong: A cross-sectional survey. J Med Internet Res. 2019;21(3):e10831. https://doi.org/10.2196/10831 PMid:30916666

25. StataCorp. Stata Statistical Software: Release 15. College Station, TX: StataCorp LLC; 2017. https://doi.org/10.7717/ peerj.4598/supp-10

26. Zhao X, Fan J, Basnyat I, Hu B. Online health information seeking using "\#COVID-19 patient seeking help" on weibo in Wuhan, China: Descriptive study. J Med Internet Res. 2020;22(10):e22910. https://doi.org/10.2196/22910
PMid:33001838

27. Riiser K, Helseth S, Haraldstad K, Torbjørnsen A, Richardsen KR. Adolescents' health literacy, health protective measures, and health-related quality of life during the COVID-19 pandemic. PLoS One. 2020;15(8):e0238161. https://doi. org/10.1101/2020.07.08.20148916 PMid:32857806

28. Karijo E, Wamugi S, Lemanyishoe S, Njuki J, Boit F, Kibui V, et al. Knowledge, attitudes, practices, and the effects of COVID-19 on health seeking behaviors among young people in Kenya. BMC Public Health. 2021;21:1020. https://doi.org/10.1186/ s12889-021-11067-2

29. Gray NJ, Klein JD, Noyce PR, Sesselberg TS, Cantrill JA. The internet: A window on adolescent health literacy. J Adolesc Health. 2005;37(3):243. https://doi.org/10.1016/j. jadohealth.2004.08.023 PMid: 16109345

30. Dunn P, Hazzard E. Technology approaches to digital health literacy. Int J Cardiol. 2019;293:294-6. PMid:31350037

31. Top F, Yigitbas C. E-health literacy level in adolescents in terms of some descriptive characteristics. Ann Med Res. 2020;27(1):340-7. https://doi.org/10.5455/annalsmedres.2019.10.680

32. Vahedi Z, Sibalis A, Sutherland JE. Are media literacy interventions effective at changing attitudes and intentions towards risky health behaviors in adolescents ? A meta-analytic review. J Adolesc. 2018;67:140-52. https://doi.org/10.1016/j. adolescence.2018.06.007

PMid:29957493

33. DeBate RD, GattoA, Rafal G. The effects of stigmaondeterminants of mental health help-seeking behaviors among male college students: An application of the information-motivation-behavioral skills model. Am J Mens Health. 2018;12(5):1286-96. https:// doi.org/10.1177/1557988318773656

PMid:29749301 